\title{
INFANCIA Y EXILIO: HISTORIAS DE VIDA DE LOS NIÑOS DE LA GUERRA CIVIL ESPAÑOLA EN BÉLGICA
}

DOI: http://dx.doi.org/10.1590/2236-3459/72904

\author{
Andrés Payà Rico' \\ 'Universitat de València (UV), València, España
}

$\cos 80$

\begin{abstract}
Resumen
Durante la Guerra Civil española (1936-1939) unos 5000 niños y niñas tuvieron que marchar al exilio, encontrando en Bélgica un nuevo hogar de acogida temporal. Al finalizar el conflicto bélico, la mayoría de ellos fueron repatriados y regresaron junto a sus familias o a centros benéfico-paternalistas franquistas. Alrededor de un millar no regresaron por diferentes motivos. Este artículo recoge el testimonio de una decena de estos "niños" hispano-belgas y sus familiares, acudiendo a la historia oral y a la memoria, para recuperar una parte de la historia de la educación y la infancia. El viaje, las colonias de acogida o la integración social, las relaciones con la familia, la escuela y la comunidad, son algunos de los temas analizados en estas historias de vida.

Palabras clave: historia de la infancia, memoria, historial oral, guerra civil española, exilio.
\end{abstract}

\section{CRIANÇAS E EXÍLIO: RELATOS DE VIDA DE CRIANÇAS DA GUERRA CIVIL ESPANHOLA NA BÉLGICA}

\section{Resumo}

Durante a Guerra Civil Espanhola (1936-1939) cerca de 5.000 crianças tiveram de exilar-se, obtendo um novo lar na Bélgica. No final da guerra, a maioria delas foram repatriados e voltaram para suas famílias ou centros de caridade franquistas. Cerca de mil não voltou por várias razões. Este artigo contém o testemunho de dez desses "filhos" hispano-belgas e suas famílias, a partir de história oral e memória, recuperando uma parte desta história da educação e da infância. A viagem, as colônias, a integração social, relações com a família, escola e comunidade são alguns dos temas discutidos nessas histórias de vida.

Palavras-chave: história da infância, memória, história oral, Guerra Civil Espanhola, exílio.

\section{CHILDHOOD AND EXILE: LIFE STORIES OF CHILDREN OF THE SPANISH CIVIL WAR IN BELGIUM}

\begin{abstract}
During the Spanish Civil War (1936-1939) about 5000 children had to go into exile, finding in Belgium a temporary foster home. At the end of the war, most of them were repatriated and returned to their families or to welfare centers of the Francoist system. About a thousand did not return for different reasons. This article gathers the testimony of a ten of these Spanish-Belgian "children" and their families, turning to oral history and memory, to recover a part of the history of education and childhood. The trip, the host colonies or the social integration, relationships with the family, the school and the community are some of the topics analyzed in these life stories.

Keywords: history of childhood, memory, oral history, Spanish Civil War, exile.
\end{abstract}




\section{ENFANTS ET EXIL: HISTOIRES DE VIE DES ENFANTS DE LA GUERRE} CIVILE ESPAGNOLE EN BELGIQUE

\section{Résumé}

Au cours de la guerre civile espagnole (1936-1939) quelque 5.000 enfants devaient partir à l'exil, trouvant une nouvelle maison d'accueil en Belgique. A la fin de la guerre, la plupart d'entre eux ont été rapatriés et rendus à leur famille ou centres de bienfaisance franquistes. Environ un millier de ne pas revenir pour plusieurs raisons. Cet article contient le témoignage de dix de ces 'enfants' Hispano-Belges et leur familières, assistent à l'histoire orale et de la mémoire, pour récupérer une partie de l'histoire de l'éducation et de l'enfance. Le voyage, l'hébergement, les colonies, l'intégration sociale, les relations avec la famille, l'école et la communauté sont quelques-uns des sujets abordés dans ces histoires de vie.

Mots-clés: histoire de l'enfance, mémoire, l'histoire orale, la guerre civile espagnole, l'exil. 


\section{El exilio de los niños españoles en Bélgica (1937-1939)}

$E$

I desarrollo de la Guerra Civil española conllevó un gran flujo migratorio y desplazamientos internos de la población infantil, siendo trasladados a colonias escolares en zonas alejadas de los bombardeos, como las ubicadas en la región valenciana (ESCRIVÁ; MAESTRE, 2011; ESCRIVÁ, 2014; SALINAS, 2014), en cuya capital se estableció el gobierno de la II República. Al mismo tiempo, y conforme avanzó la guerra, otros se marcharon al extranjero, una alternativa de protección a la infancia que fue masiva en los últimos años del conflicto fratricida. Varios fueron los países de destino de estos niños y niñas, ya fuera en colonias o en familias de acogida. Así fue como Inglaterra, Suiza, Dinamarca, la Unión Soviética, México, Francia y, como estudiaremos a continuación, Bélgica (EECKHOUT, 1987; BERGUER, 1991; LABAJOS; VICTORIA, 1997; ALONSO, 1998; ELOY, 2005; ALTED; GONZÁLEZ; MILLÁN, 2003; ALTED, 2005; PAYÀ, 2013) se convirtieron en el nuevo hogar de esta población desplazada.

Afortunadamente estos hechos están siendo fruto de numerosas investigaciones y publicaciones en la actualidad (BARRENETXEA, 2012; ARAGÜES, 2015; PAYÀ, 2015), recuperando así muchas historias de vida de estos niños y niñas que tuvieron que abandonar su país. En este sentido, quisiéramos realizar una aportación a la materia, fijando nuestra mirada en aquellos que se desplazaron a Bélgica y decidieron no regresar. La mayoría de ellos, como veremos en el análisis de las entrevistas, procedían del País Vasco. (LEGARRETA, 1987a, 1987b; BELL, 2011). El infame bombardeo de Guernica de 1937, cuyo horror inspiró la famosa obra de Picasso, aceleró las evacuaciones en grandes buques (como el "Habana", "Goizeko-Izarra" y "Cabo Corona"), gracias a la escolta de la armada inglesa y el beneplácito del gobierno francés en cuyos puertos atracaron. Paralelamente desde Cataluña, en tren, camiones y barcos, también partieron una gran cantidad de menores en el conocido como "éxodo final" entre enero y febrero de 1939.

Al llegar a Francia, pasaban un examen médico de reconocimiento y se les proporcionaban vacunas, alimento y ropas adecuadas. Algunos de estos niños pasaron un periodo de adaptación y mejora de salud en colonias francesas antes de ser trasladados en tren a Bélgica, entre las cuales destacaron por el alto número de niños acogidos la "Maison Heureuse" en la Ille d'Olèron, "Domaine de Magenta" en Moliets-et-Maa, "Le Hameau des Écureuils" en Capbreton y "Val d'Or". Otros fueron trasladados directamente a las colonias ubicadas en la costa belga, como "Home Emile Vandervelde" en Oostduinkerke, "Home de Vacances" en Heyst-aan-Zee, "L'Age Heureux" en Niewport y "Maison de Repos" en Groenendijk, o bien fueron distribuidos en las mismas estaciones de tren belgas a las familias de acogida.

El auténtico protagonista de esta acogida a los niños españoles en Bélgica, fue la ciudadanía, así, tanto familias particulares, como los sindicatos y las asociaciones nacionales e internacionales, se movilizaron para hacer realidad esta labor humanitaria. Entre estos colectivos, cabe destacar la labor del partido socialista belga Parti Ouvrier Belge- Belgische Werkliedenpartij (POB-BWP), organizando en abril de 1937 a través de las Femmes Prévoyantes Socialistes así como con otros partidos y sindicatos de izquierdas, el Comité National pour l'Hébergement des Enfants Espagnols en Belgique (CNHEEB).

De otra parte, aunque no es el caso de las historias de vida que aquí analizamos, los sectores católicos belgas también realizaron una destacada iniciativa de acogida con 
los niños y niñas vascos. Fruto del contacto de Mateo Múgica, Obispo de Vitoria con Van Roey, Cardenal Arzobispo de Malinas, se creó el Baskisch Kinderwerk-L'Oeuvre des enfants basques, contando asimismo con la colaboración de organizaciones católicas como la Jeunesse Ouvrière Chrétienne (JOC), Soeurs de la Charité, Filles de la Charité, Cáritas, la Sociedad Saint Vincent de Paul y, fundamentalmente, de las familias católicas belgas que acogieron más de un millar de niños y niñas.

Otras iniciativas, menos numerosas aunque igualmente importantes, fueron las que llevaron a cabo: el Departamento de Asistencia Social del Gobierno de Euskadi y el Comité Belga-Vasco de la embajada de España en Bruselas; la Cruz Roja de Bélgica por medio del Comité Belge d'Asistance aux Enfants d'Espagne; la solidaridad comunista mediante el Socorro Rojo Internacional; la sección belga de la Office Internationale pour l'Enfance (OIE); y el Grupo Español para la Defensa de la República, creado por la Casa de España de Bélgica junto al Gobierno de la II República española.

Al finalizar la Guerra Civil, la mayoría de los niños fueron repatriados a España. Sin embargo, por diferentes motivos (fallecimiento o prisión de los padres, la desastrosa situación económica y política española, el miedo a las posibles represalias franquistas, la petición de los propios padres biológicos, la voluntad de las familias de acogida de realizar una adopción permanente, etc.) unos 1.300 nunca volvieron a España o bien regresaron con posterioridad para establecer su residencia en Bélgica de manera permanente. El testimonio y la memoria -ya frágil, filtrada por el olvido intencional o no, y con las reservas que la historia oral tiene - (EGIDO, 2001, 2009; GAGO, 2007; DE DIOS, 2015) de dos "niñas" (Germana Contreras Miravalles y Elvira Fernández Alonso), tres "niños" (Néstor Folla, Carlos Pascual Madorran y Santiago Roldán Aragón), la esposa de un "niño" (Jacqueline Van Overbeke - mujer de Ángel Múgica -) y seis hijos de los "niños" exiliados (Patrick Fakkel y Carmen Fakkel - hijos de Carmen Mirantes -, Johnny Larrea Betolaza hijo de Abundio Larrea -, Manuel Múgica González - hijo de Ángel Múgica -, Jenny Folla hija de Néstor Folla - y Teresa Pérez Diego - hija de Francisco Pérez -), nos ayudarán a continuación a recuperar nueve historias de vida (cinco de ellas narradas en primera persona).

\section{Historias de la infancia en el exilio: Un nuevo país, una nueva vida}

Ahora que se cumplen 80 años del mencionado movimiento migratorio infantil, hemos querido realizar un estudio pormenorizado de estas historias de vida, recuperadas gracias al trabajo de investigación llevado a cabo en el curso 2011-2012 en la Universiteit Gent. Un proceso lento y laborioso de recuperación de la memoria histórica española en el exilio del que nos hemos ocupado con anterioridad (PAYÀ, 2013, 2015), que contó con la inestimable colaboración del alumnado ${ }^{1}$ de dicha universidad por motivos idiomáticos, pues estos "niños" y "niñas" entonces octogenarios o nonagenarios, habían olvidado en muchos casos su lengua materna (español) y desde hacía ya muchas décadas utilizaban el neerlandés como lengua vehicular. La gran cantidad de horas de grabación de estas entrevistas semiestructuradas (casi 20 horas de duración), la transcripción de las mismas,

\footnotetext{
${ }^{1}$ Las entrevistas a "niños/as" y sus familiares, fueron realizadas en Gante y otras poblaciones del Flandes belga, entre los meses de enero a marzo de 2012, aprovechamos aquí para agradecer la labor en la realización de las entrevistas a: Lore Arnauts, Cyrina Grimonprez, Elise Ryckebusch, Elle Winten, Jelmen Haaze Ward Vandelberghe, Liesbeth Hoedt y Jorre Van de Sompele.
} 
su correcta traducción al español y el análisis de contenido de dichas historias de vida, han demorado el estudio pormenorizado de cada una de ellas hasta la fecha. Por ello, tras más de tres cuartos de siglo, queremos realizar ahora con este artículo un ejercicio de memoria histórica y homenaje a estos entrevistados que, por el inexorable paso del tiempo, están desapareciendo. Así pues, con el rigor académico e histórico necesario, y gracias a la triangulación de la información con otras fuentes obtenidas en la investigación (fotografías, correspondencia, dibujos infantiles, noticias en prensa, publicaciones, etc.), pasamos a realizar un análisis temático de las historias de vida de estos niños y niñas españoles que, por diferentes motivos, establecieron su residencia de manera definitiva en Bélgica.

\title{
2.1. El viaje a Bélgica: Un largo e incierto desplazamiento lleno de miedo y esperanza
}

Cuando el 26 de abril de 1937 la situación de la Guerra Civil tuvo un giro dramático afectando, aún más si cabe, a la población civil con el bombardeo del ejército nazi de Guernica (País Vasco), las autoridades y familias decidieron evacuar a la población infantil. Así ocurrió en el caso de Néstor Folla, quién recuerda que Bilbao era "bombardeada, por desgracia, los alemanes bombardearon todo varias veces. Felizmente para nosotros, vivíamos un poco fuera de la ciudad, en la montaña. Así que en esta zona estábamos relativamente seguros. Pero debido a las circunstancias, se organizó la evacuación de los niños". (FOLLA, 2012). La misma experiencia traumática es recordada en primera persona por Santiago Roldán, quien manifiesta con total claridad la posición estratégica de Bilbao "una especie de hoyo, rodeado de montañas, de manera tal que no podían entrar, por lo que amenazaron con bombardear toda la ciudad como en Guernica" (ROLDÁN, 2012); por su parte, Manuel Múgica, relata también cómo su padre tuvo que vivir una situación dramática fruto de los horrores de la guerra:

\begin{abstract}
Mientras mi padre estaba allí, los soldados invadieron la escuela y hubo un gran tiroteo. Hubo un disparo en la pierna... muchos niños fueron en realidad asesinados... y sus padres dijeron: "es demasiado peligroso estar aquí. Vamos a ir a Bilbao, con la familia", una abuela y una tía que vivía en Bilbao. Se trasladaron a pie por las montañas hasta Bilbao. Aproximadamente a $120 \mathrm{~km}$. Él no recordaba cuánto tiempo tardaron en el trayecto. Al llegar a la casa de su tía y abuela, donde iban a alojarse, estaba bombardeada. Estuvieron revisando entre los escombros. Así que era la segunda vez que se escapó de la muerte y luego del bombardeo de Guernica del 26 de abril... por lo que el gobierno decidió llevar a los niños en... a evacuar. Por eso se decidieron luego sus padres para llevarlo a un lugar seguro. (MÚGICA, 2012).
\end{abstract}

Una vez tomada la decisión de evacuar a la infancia para su protección, las autoridades y la población civil se puso en marcha, movilizando las instituciones anteriormente descritas y organizando el viaje hacia Bélgica con parada en Francia. Los "niños" y sus familiares recuerdan que este traslado se realizó en grandes barcos, ya fueran buques mercantes, de guerra o en corbetas. Aquellos que no residían en la ciudad de Bilbao, como era el caso de Francisco Pérez, tuvieron que realizar los preparativos pertinentes "ir a Bilbao e inscribirse para tener un pasaporte, una pequeña identidad y ser llevados allí en pequeñas corbetas". (PÉREZ, 2012). Su hija Teresa, describe perfectamente la rapidez de la evacuación y las dramáticas despedidas de las familias: "necesitaban una salida, por lo que todo iba muy rápido. Fueron casi arrancados de la 
madre. Esto era para mi padre un momento muy difícil de contar, entonces le saltaban las lágrimas de los ojos. Y ver a mi padre llorar, era una cosa muy infrecuente..." (PÉREZ, 2012), una situación realmente dramática y desgarradora.

Los barcos, que no estaban concebidos para trasladar pasajeros sino con otros fines comerciales o bélicos, se encontraban absolutamente abarrotados como manifiesta Teresa Pérez, "estaban allí con una gran cantidad de niños, el agua era salvaje e iban de un lado a otro y estaban vomitando. Era un gran barco, y lo describió como un... un barco inglés". (PÉREZ, 2012). Este hacinamiento es fácilmente imaginable, si seguimos las declaraciones de Carmen Fakkel, quien describe que los niños se encontraban "como ovejas... por la noche, con un poco de miedo. Un barco estaba esperando allí, por lo que te sientes como una oveja, que no sabe nada, te despiertas a la noche y estás en un espacio de carga. Te despierta el mar con gran pánico, los niños así fueron despertados por el ruido, y las olas de la alta mar". (FAKKEL, 2012). Los niños y niñas evacuados no eran conscientes del motivo por el cual estaban allí ni en qué consistía el viaje. A la incomprensión y tristeza por despedirse de sus padres y familiares, se unía la falta de preparación material y psicológica para el traslado, como narra Néstor Folla al preguntarle sobre ¿cómo vivió ese viaje?, su respuesta es desoladora: "me dieron un trozo de pan para el camino, eso era todo". (FOLLA, 2012). Al miedo, desconocimiento, tristeza e incertidumbre, se contrapone afortunadamente, la buena predisposición y el trato brindado por los soldados del buque y los adultos que les acompañaron. Valga el relato de Manuel Múgica sobre la experiencia de su padre Ángel para ilustrar lo señalado:

Los niños estaban asustados. En primer lugar, era un caos, porque en ese barco todo era un ir y venir. Mientras tanto les dispararon... así que era un completo caos. Estos niños no sabían lo que sucedía. A mi padre le había dado una cesta mi abuelo con algo de comida y ropa limpia. Pero él lo perdió en el barco mientras les atacaron, perdida la cesta, lo perdió todo... El mar estaba bastante movido, por lo que la mayoría de los niños estaban mareados. Los soldados trataron de animar a los niños pequeños proyectando películas de Popeye. Sí, sí, era un buque de guerra inglés, pero pusieron dibujos animados de Popeye para mantener a esos niños ocupados. Mi padre siempre recordaba cómo fueron atacados desde tierra, y que otros barcos alemanes también atacaban, aunque eran generalmente falsas alarmas. Pero esto provocaba un gran pánico. (MÚGICA, 2012).

Una vez acabado el trayecto en barco, los niños españoles llegaron a las costas francesas, generalmente Olerón, donde nada más llegar, Carlos Pascual tuvo una sensación muy positiva "me acuerdo de un pequeño episodio para mí. Cuando llegamos a tierra y puse los pies en la orilla estaba muy limpio de nuevo. Eso es algo que me quedó grabado". (PASCUAL, 2012). Tras el pertinente reconocimiento médico, fueron trasladados de nuevo a las costas belgas, en donde fueron acogidos provisionalmente en colonias habilitadas al efecto para recuperarse física y mentalmente antes de ser recibidos por las familias. Su estancia en la colonia la recuerdan de una manera muy agradable, pues tuvieron oportunidad de jugar en la playa, recibir algunas lecciones y descansar de un viaje tan traumático. Así cuenta Teresa Pérez la experiencia de su padre, "estaban allí para tomar algunas clases, se les permitió jugar. Fue un poco para recuperar, pero fueron bien tratados. Había adultos que les acompañan en su viaje en la medida en que era necesario Él recordaba la experiencia como divertida y, sobre todo debido a que aún se encontraba dentro del grupo de niños españoles y todavía podía comunicarse". (PÉREZ, 2012). Por su parte, los recuerdos de Santiago Roldán son más difusos aunque también muy agradables, 
"fue justo detrás de la playa. Jugando allí en las dunas... en la colonia, fueron en realidad dos semanas divertidas y jugando en la playa". (ROLDÁN, 2012). Por lo analizado en las fotografías y tarjetas postales propagandísticas que se custodian en el instituto de historia social Amsab-ISG de Gante, y que tuvimos la oportunidad de consultar, las instalaciones de las colonias de acogida contaban con una dotación muy completa, realizando en las mismas un variado conjunto de actividades pedagógicas, higienistas, lúdicas y de ocio. Finalmente, tras este breve periodo de recuperación, los diferentes grupos de niños y niñas fueron trasladados en ferrocarril a las estaciones donde les esperaban las autoridades y familias para brindarles una calurosa acogida, poniendo así fin a este largo viaje de España a Bélgica.

\subsection{La recepción y acogida: Una nueva familia para una nueva vida}

Todas las historias de vida analizadas recuerdan muy gratamente la recepción que tuvieron al llegar a las ciudades de acogida -en la mayoría de los casos estudiados, Gante. A los sentimientos de miedo e incertidumbre, pronto se sumaron los de alegría y esperanza por reencontrarse con otras familias que les acogieron con los brazos abiertos. Johnny Betolaza, hijo de Abundio, recuerda que su padre le contó en varias ocasiones su llegada al Vooruit, el emblemático centro de festivales y arte del movimiento obrero de Gante, que contaba un salón de baile, un cine y un teatro: "donde hicieron el cine y dieron conferencias. Me contaba que había muchas personas que eran los padres adoptivos que iban detrás de ellos y que tenían un cartel que identificaba las familias para los que estaban destinados". (BERTOLAZA, 2012). Del mismo modo, la esposa de Ángel Múgica, describe una escena parecida, en la que "cuando llegaron, los padres adoptivos estaban todos en la sala y los niños se sentaron en sillas en el escenario y tenían una tarjeta de este tipo... llamaban entonces a los padres de acogida y se encontraban con cada niño". (MÚGICA, 2012). Sin duda, es Elvira Fernández, quien recuerda de primera mano con más detalle su llegada desde la estación central de Gante, el paseo por las calles de la ciudad con una rosa símbolo del partido socialista que había organizado la acogida, la llegada hasta el teatro Vooruit y el encuentro de las nuevas familias belgas con los niños y niñas venidos de España:

\footnotetext{
Y todos teníamos una flor, no sé por qué... Y desde Sint-Pieters al teatro del pueblo fuimos caminando... ¡toda la gente estaba allí en la calle! ¡Pero la gente en la calle! Para nosotros... era una auténtica agitación. Y estábamos allí en el escenario, sí. Y había una cortina que se levantó poco a poco. Y todos estábamos allí y con una tarjeta identificativa con nuestro nombre y nuestro lugar de nacimiento o fecha de nacimiento, no sé. Y mi padre estaba allí. Y en un momento se abrió el telón y se podía pasar, con un gran escándalo entre las personas que estaban allí. ¡Y sin embargo era genial! (FERNÁNDEZ, 2012).
}

En ese mismo momento, algunos niños y niñas españoles vivieron un momento muy traumático y doloroso, pues todas las familias no pudieron hacerse cargo de varios hermanos aunque hubiesen venido juntos, teniendo que separarse entre sí, incumpliendo la promesa que les habían hecho a sus padres naturales o familias al despedirse en España. Así describe Jacqueline Van Overbeke la experiencia de su marido, "le dijo su padre que nunca se separaran el uno del otro. En cambio en Gante se separaron: uno fue con una familia, y su hermano con otra... y cada uno en una familia diferente y esto al 
parecer fue un drama". (VAN OBERBEKE, 2012). Afortunadamente, aunque no residieran juntos bajo un mismo techo, los hermanos coincidían en otros momentos, no siendo tan dramáticas estas separaciones, por ser temporales y atenuadas por estos encuentros.

Las familias de acogida, generalmente de clase obrera y con vinculación con el partido socialista belga, a pesar de sus estrecheces económicas brindaron un excelente trato a los niños y niñas españoles. Así lo recuerdan y valoran la mayoría, como sucede en el caso de Johnny Betolaza, "hubo gente que dijo, es sólo por tres meses, lo llevaremos... pero no fueron tres meses, esas personas no eran absolutamente ricas, eran pobres, pero lo hicieron muy bien, ayudaron" (BETOLAZA, 2012), o Teresa Pérez, que nos cuenta cómo "papá vio a los padres realmente como sus propios padres y no padres realmente adoptivos. Con plena confianza y si ellos mismos nunca habían tenido hijos, toda la atención se dirigió al niño que había venido de España. De hecho, afirmó que siempre se le ha tratado bien". (PÉREZ, 2012). Declaraciones similares de todas las historias de vida estudiadas, recuerdan con mucho cariño y valoran excepcionalmente la tarea de estas familias de acogida: "eran dos personas fantásticas, ambos, en realidad" (FERNÁNDEZ, 2012), "siempre ha tenido maravillosos padres adoptivos" (FAKKEL, 2012), "me dejaron estudiar, me han aceptado como su propio hijo. Fueron gente muy agradecida" (FOLLA, 2012), "tenía muy buenos padres adoptivos. Tuvieron un hijo y yo era como un hijo más. Mi padre adoptivo era en realidad... No sabía que era padre adoptivo. Y estaba en lo cierto que era su propio hijo". (PASCUAL, 2012). Sin embargo, en algunos casos, pocos pero existieron, algunas familias aprovecharon la ocasión para intentar obtener "mano de obra barata" y acoger a niños españoles con la intención de encontrar en ellos una ayuda laboral en sus maltrechas economías, ayudando en trabajo en las granjas o la peluquería, por ejemplo.

\subsection{La educación y los profesores: El necesario proceso de adaptación e integración}

Una vez los niños y niñas españoles se hallaban acomodados en los hogares de sus familias de acogida, a pesar de la buena voluntad y del afecto recibido por los "nuevos" padres belgas, se empezaron a encontrar con las primeras dificultades de adaptación a un nuevo país, nuevas costumbres y nueva lengua. Surgieron aquí algunos episodios de rechazo al diferente, al otro, al extranjero... propios de un proceso de adaptación en la Europa de los años 30 del pasado siglo. Estos episodios, aunque temporales y no representativos del clima general de acogida, sucedieron y como tal nos los han descrito en las entrevistas analizadas. Así, Elvira Fernández relata "la integración... fácil, fácil. Uno estaba allí. En un principio, por supuesto, te miran y yo tenía el pelo negro y debido a sus muchos rizos, la piel oscura más oscura que ahora..." (FERNÁNDEZ, 2012), del mismo modo, Carmen Fakkel describe que "los niños son siempre un poco crueles. Oye... que no se dan cuenta. Por supuesto, al principio no estaba tan bien" (FAKKEL, 2012) y Manuel Múgica nos cuenta cómo su padre Ángel "no fue muy bien recibido por todas las personas en el barrio que lo trataron como 'sustancia viscosa' y no tenían mucha simpatía por él". (MÚGICA, 2012).

Estas actitudes y comportamientos de algunos que minusvaloraban o no trataban con el respecto debido a los recién llegados, se agravaban por aspectos externos, como por ejemplo el pelo, pues a los niños se les rapó el cabello en las colonias de acogida anteriormente descritas para eliminar o prevenir los piojos, lo cual les hacía fácilmente 
identificables y les convirtió en objeto de burla: "Hubo también un problema, ya que me llevaron a la peluquería. Mi cabello estaba rapado y comenzó a crecer un poco, entonces tuve que ir a la peluquería. Esto fue una catástrofe. Fui corriendo por la calle. Y los niños me siguieron. $Y$ todos los estudiantes caminaban detrás de mí. $Y$ me dio vergüenza, toda la escuela estaba mirándome". (BETOLAZA, 2012). La imagen peyorativa sobre los españoles por parte de algunos, especialmente agravada por la crueldad infantil, se fundamentaba en la supuesta falta de higiene, la cual era motivo de insulto y burla, como cuenta Néstor Folla, "si estás con los niños jugando en la calle, y si accidentalmente fallabas o algo en el fútbol, otros niños te llamaban sucio español. Eso duele. ¿Por qué? Los otros niños daban pisotones en el fútbol y no decían nada, pero si lo hacía un español, era un sucio español. Esa palabra "sucio español" la oí docenas de veces, pero dolía. No discutí porque me producía dolor". (FOLLA, 2012). Un caso muy similar relata Teresa Pérez sobre su padre:

\begin{abstract}
Aunque en realidad vivía aquí, era español de España, pero era belga. Estaba en realidad en el extranjero en todas partes. Sí, porque del español se tenía una imagen muy negativa. Mi padre no podía soportar cuando lo llamaban "el español". Una vez había un chico de su edad iba en bicicleta y les dijo a la familia "sucio español". De hecho, eran los únicos extranjeros y siempre que algo pasaba, decían que habrían sido los españoles. Como ahora con los turcos y los marroquíes, pasaba con nosotros, aunque en realidad nunca tuvo problemas, pero para todos los vecinos, eran los españoles. $Y$ vinieron a menudo a interrogarnos y mi madre tenía un gran temor a la policía. (PÉREZ, 2012).
\end{abstract}

Afortunadamente, éstos eran episodios aislados y gracias a la escolarización y la educación recibida, gradualmente estos problemas fueron desapareciendo. Fue la formación y el aprendizaje de una nueva lengua, así como la convivencia con otros compañeros de clase belgas, la que permitió a estos niños y niñas españoles adaptarse e integrarse en la sociedad de acogida. En este sentido cabe destacar la figura de los maestros, profesores, adultos o padres que con paciencia y constancia facilitaron esta tarea de adaptación mediante la educación. Todo son palabras de elogio hacia estas figuras educadoras tan importantes: "fue también un maestro de esa escuela. Ese hombre tenía tal paciencia" (BETOLAZA, 2012), "era muy feliz, hacían todo lo posible en la escuela y los maestros... fueron los maestros lo que hicieron los esfuerzos adicionales para que pudiese aprender el holandés" (MÚGICA, 2012), "mi padre era maestro y... tuvimos suerte y lo hizo bien. Mi padre llegó junto con los niños, con un profesor y dos profesores que teníamos" (FERNÁNDEZ, 2012), "mi maestro, el esplendor de un maestro, muy conocido en Amberes... Paco Martínez, donostiarra. Felicitaciones a este caballero". (FOLLA, 2012).

Gracias a la labor de los docentes, los niños pudieron adaptarse gradualmente a la escuela, pues el desconocimiento del idioma vehicular, hacía que al inicio con una incorporación progresiva estuviesen en niveles inferiores al que les habría de corresponder por su edad, aunque pronto pudieron seguir las clases con normalidad: "pero poco a poco, y allí estaba él, que podía ir a la escuela, pero no todos los días de la semana y fue sobre todo para los niños españoles" (PÉREZ, 2012), "el primer año obviamente fue difícil, el primer año, pero su segundo año era ya muy buen estudiante ¿La primera clase? Sí, era especial porque era español" (VAN OVERBEKE, 2012), "no tuve absolutamente ningún problema. Pero en realidad tenía que ir al sexto año, aunque fui al cuarto" (FERNÁNDEZ, 2012), "fue a la escuela aquí... Ilegó un 11 de julio y al mes y medio más o menos comenzó 
la escuela. Fue una transición muy rápida... fue una suerte que le dejaran ir al primer año, ni siquiera se podía expresar" (FAKKEL, 2012), "la maestra dio sus lecciones y no entendía nada y luego recogió su diccionario. Con el diccionario fue muy rápido. Pero cuando empezó a ir a la escuela la lección ya había comenzado... Había perdido demasiados días por lo que escuchaba y no entendía. Pero, en realidad, poco más se le podía pedir a un niño". (BETOLAZA, 2012). Sin embargo, a pesar de las dificultades señaladas de integración, y gracias al trabajo pedagógico de maestros, la mayoría de los entrevistados y sus familiares coinciden en que, una vez superados estos obstáculos, les gustaba la escuela y ésta les sirvió para poder adaptarse a su nueva vida.

\subsection{La lengua: El neerlandés un idioma totalmente diferente}

Sin lugar a dudas, la dificultad más grande a la que tuvieron que enfrentarse los niños y niñas y sus familias de acogida, fue el idioma. Al tratarse de Flandes, la zona norte de Bélgica, la lengua utilizada era el neerlandés, muy diferente fonética y gramaticalmente al español, "el flamenco no tiene nada que ver con nuestra lengua latina. Porque si dices francés... eso es casi igual, es similar a la italiana. Es como la lengua vasca y española. Conozco a un montón de personas que querían aprender el idioma y han abandonado". (BETOLAZA, 2012). La infancia exiliada pasó de no entender nada a "olvidar el español por completo" (FERNÁNDEZ, 2012), aunque al principio reconocen que "el holandés era un idioma difícil. Yo podría tener un pensamiento especial, pero el español es más fácil hablar y leer. Todo lo que se habla se puede leer. El holandés ha sido muy difícil". (FOLLA, 2012). Para su aprendizaje se recurrió a diferentes estrategias, ya fuera la mímica "el principio fue muy difícil porque no podían comunicarse entre sí, lo hicieron con gestos" (PÉREZ, 2012) o bien el uso de diccionarios y vocabularios o sencillos manuales de conversación que se habían editado en las tres lenguas (español-vasco-holandés) y que fueron muy útiles en los primeros meses, fundamentalmente para la comunicación básica con las familias. En este sentido, fue la escuela una vez más, la mejor estrategia de enseñanza-aprendizaje de la lengua, realizando inicialmente clases en español, para pasar posteriormente a la inmersión lingüística en holandés:

Tenía que aprender flamenco. $Y$ en la escuela lo pudo hacer sin problemas. $Y$ cuando conoció a mi madre, le decía "ah, ¿tú eres español, y hablas flamenco?" "No, no, no hablo flamenco". Esa fue la primera cosa que aprendió. "¿Hablas flamenco?" "no no". Pero ese aprendizaje fue rápido. "Un poco, un poco, pero lo entiendo bien". No se puede imaginar si tienes la obligación, lo rápido que va el aprendizaje. Eso es como decir, 'No puedo hablar Inglés, voy a Inglaterra". (BETOLAZA, 2012).

\subsection{Usos y costumbres: alimentación, salud, política y religión}

La necesaria adaptación y la lengua no fueron los únicos cambios a los que tuvieron que acostumbrarse lo más rápido posible los niños y niñas españoles. Otros elementos del día a día pertenecientes a la cultura belga, así como a sus usos y costumbres, supusieron también un "choque cultural", en una época en la que la globalización no existía, las fronteras eran mucho más marcadas y las diferencias de hábitos entre países europeos eran mayores que sus similitudes. Con total seguridad, podemos afirmar tras el estudio de las historias de vida, que el tema de la alimentación y la salud, especialmente el de la comida y la gastronomía, fue una de las materias que más impactó en la infancia exiliada, 
más si cabe, al provenir de un país marcado por las circunstancias excepcionales de una guerra:

\begin{abstract}
Aquí nunca han pasado hambre. Pero en España existía el racionamiento. Teníamos un recibo y no se podía comprar de contrabando. Mucha juventud murió porque no tenían suficiente comida. Y aquí no había, pero con la II Guerra Mundial en 1947 hubo racionamiento. Lo único que no estaba racionado era el chocolate. No comió tanto chocolate en su vida. La madre adoptiva le dijo que tenía que comer porque estaba demasiado delgado, $47 \mathrm{~kg}$ para un chico es demasiado delgado. Pero no engordaba. Aquí tampoco. Había muchas cosas que no le gusta comer. La comida era muy diferente: col roja, espárragos, achicoria... (BETOLAZA, 2012).
\end{abstract}

Como hemos visto anteriormente, la mayoría de las familias de acogida, pertenecían a la clase trabajadora y, además de tener varios hijos, la economía doméstica era bastante ajustada. A pesar de ello, realizaron un esfuerzo extra para poder alimentar también a sus nuevos "hijos" adoptivos españoles, como manifiesta Teresa Pérez al afirmar que eran "una familia con varios hijos, y lo que hemos oído es que probablemente no tenían suficiente comida para alimentar a todas esas bocas". (PÉREZ, 2012). Del mismo modo, también Néstor Folla, cuenta que "me dieron de comer, si tienes hambre comes de todo. Éramos siete en el hogar, y el pan se dividió en ocho. Tenía una pieza y era para todo el día. Entonces eres un chico de siete-ocho años, y tienes hambre". (FOLLA, 2012). Sobre los alimentos, los niños y sus familiares recuerdan la achicoria, la mantequilla, el pescado, la pasta, las coles de Bruselas, la carne roja, las patatas fritas... los cuales no estaban acostumbrados a comer en España. Contentos por poder comer todos los días y con una gran variedad de productos, no solo se tuvieron que habituar a la nueva dieta alimenticia belga, sino también a sus horarios:

Una gran diferencia era que nosotros comíamos muy tarde en España, y aquí ya a las cinco o seis de la tarde estabas cenando. Para mí era demasiado pronto. - ¿Era buena la comida aquí? Sí, sin duda. Era completamente diferente, pero yo me crié con gente muy pobre en España. Así que aprendí que todos comían, y comían de todo. No hay nada que no me vaya a comer, no hay nada, yo no puedo decir eso. Tienes hambre, y picas una o dos veces porque hay que aguantar todo el día. Cuando había patatas fritas, yo me ponía muy contento. (FOLLA, 2012).

La abundante comida y una alimentación más variada contribuyeron, junto al ejercicio físico y el juego al aire libre, a una mejora sustancial en la salud de los niños y niños que venían sufriendo la carestía, escasez y racionamiento propios de una guerra. Es fácil imaginar cuál era su estado de salud al llegar, si tenemos presente lo explícito de sus relatos al respecto: "hubo un reconocimiento médico, y también se ve que había gente que... los niños tenían pulgas" (DIEGO, 2012); "cuando llegaron allí, todos ellos fueron afeitados. Probablemente por los piojos y todo". (VAN OVERBEKE, 2012). Por suerte, esta situación cambió -aunque cuando llegó la Segunda Guerra Mundial volvió a ser difícil de nuevo- e, independientemente del nivel socioeconómico de las familias de acogida, los niños y niñas españoles tuvieron la atención alimentaria y de salud adecuada.

Otro de los aspectos que aparecen constantemente en los relatos sobre las costumbres culturales a las que se tuvieron que adaptar, son los relativos a la política y la religión. Como vimos al inicio de este estudio, la mayoría de niños y niñas procedían del País Vasco, donde el catolicismo estaba muy presente y arraigado. Una realidad religiosa que contrasta mucho con la vivida en Bélgica: "mi padre procedía de una familia socialista 
y mi madre de una familia muy católica. Los dos opuestos" (PÉREZ, 2012)"; "comunistas, comunistas. Sin fe, sin duda no" (MÚGICA, 2012); "el grupo era de los socialistas. Así que estábamos en el lado de la República, que no quiere decir que no eran cristianos. Pero mi madre iba a misa [...] en Gante no, mis padres adoptivos eran socialistas. Y no creían. La fe y la política no eran compatibles" (BETOLAZA, 2012); "tuve padres adoptivos que fueron bautizados pero eran librepensadores, aunque ninguno iba a la iglesia, ellos también han sido enterrados en la iglesia". (FAKKEL, 2012). El testimonio de Elvira Fernández, demuestra cómo las prácticas religiosas no eran tan habituales en su nuevo país de residencia, contrastando sobremanera con las vividas en la España nacional-catolicista del franquismo a su regreso tras más de una década viviendo en Bélgica con costumbres mucho más laicas:

\begin{abstract}
Yo fui bautizada. Eh? Pero no voy a la iglesia. Yo sé que mi madre, cuando iba a la cama, ella tenía un reclinatorio. Pero eso fue en mi infancia. Sí, lo sé, mamá y papá tampoco iban a la iglesia [...] Sí, España es católica, pero ahora mucho ya no sé. La primera vez que volví allí, era en 1948. Fui allí para conocer a mi futura familia política. Y estaba llena de iglesias, y los católicos... Eso fue terrible, eh. Eso fue demasiado. Ellos cuando alguien está muriendo llaman al pastor. Llegó con un sombrero y de blanco, con un palo y dos niños detrás y todos tenían que arrodillarse. Era terrible. Pero cada niño hace su comunión. Para ellos es una fiesta para ese niño. Católica o no, el niño debe hacer su comunión. (FERNÁNDEZ, 2012).
\end{abstract}

\title{
2.6 El planteamiento del retorno a España
}

En algún momento, tras los años vividos en Bélgica y tras rehacer su vida de nuevo en otro lugar, estos niños y niñas se plantearon regresar a España. Antes o después, esta posibilidad surgía en alguna ocasión, aunque por diferentes motivos, las historias de vida que aquí estudiamos, decidieron proseguir en un país que les había recibido con los brazos abiertos. Lo cierto es que era muy duro empezar de nuevo por segunda vez una nueva vida, "su madre siempre quiso volver a España. $Y$ fuimos a España con la idea de iniciar un negocio. Pero después de dos semanas, Carlos no estaba allí, no se quedaría allí. No conocía a nadie, todos sus amigos estaban aquí". (PASCUAL, 2012). La situación económica y laboral contrastaba mucho en los años de la posguerra española, como nos relata Teresa Pérez, al regresar temporalmente a España, su madre tuvo que dedicarse a hacer de ama de cría o nodriza y su padre a trabajos mal remunerados "en España no había nada, tú no podías trabajar, había más desempleo. Mi madre para conseguir el dinero, dio leche a los niños cuya madre no podía amamantar, principalmente ricos [...] trabajaron en España, así como en comercio... y estaban allí no sólo mal pagados, sino también mal tratados" (PÉREZ, 2012), por lo cual decidieron volver definitivamente y establecer su residencia de nuevo en Bélgica. Así pues, las dificultades laborales y el desarraigo familiar, fueron motivos suficientes que llevaron a muchos a permanecer en Bélgica:

Sí, sí. La mayoría han vuelto, pero mi padre entonces había fallecido... mi madre había huido a Francia. No tenía a nadie en España. ¿Qué podía hacer en España? Mis hermanas también vivían en Francia, también se fueron de España. Pero sí, no tenía en España nadie más. Tenía una vida hermosa aquí. Si hubiera vuelto a España, inmediatamente hubiera tenido que trabajar en las minas. Aquí en Bélgica asistí a la escuela de comercio. (FOLLA, 2012).

Otras, como Elvira Fernández, se vieron forzadas a regresar a Bélgica, tras veintiún 
años de nuevo en España (de 1979 al 2000) por motivos de salud, pues su marido estaba enfermo y el médico les recomendó volver, si no hubiese sido por esta causa de fuerza mayor, "de lo contrario, estaría todavía en España. No hubiera vendido mi piso. Tenía un hermoso apartamento. La vida allí es también mucho más agradable. Mucho más agradable. Sí, el clima es mucho mejor...". (FERNÁNDEZ, 2012). Queda patente así en los testimonios estudiados que, aunque la vida en Bélgica y el trato recibido era muy bueno, todo exiliado tiene el legítimo deseo de regresar a su país de origen, pero motivos económicos, laborales, familiares, de salud, políticos o personales, esto no siempre es posible y llevan a muchos a tener que permanecer en el país de acogida de manera permanente.

\section{Retrospectiva y consideraciones finales: Reflexiones sobre toda una vida}

Por lo analizado aquí, podemos apreciar claramente una pequeña parte de lo que supuso para estos niños y niñas el hecho de tener que marchar al exilio y adaptarse a un nuevo país en el que la lengua, la educación, los hábitos y las costumbres eran bien distintos a los de su lugar de nacimiento y primeros años de vida. Ocho décadas después, hemos intentado ayudarles a volver la mirada atrás $\mathrm{y}$, haciendo uso de la memoria y marcados por el olvido, intencional o no, valorar a modo de retrospectiva aquellos años iniciales que tanto marcaron su infancia y vida posterior. Toda una historia de la educación formal y no formal, que les llevó a adaptarse a unas nuevas circunstancias, con la ayuda de sus familias de acogida.

Para finalizar este artículo nos gustaría destacar algunas de estas reflexiones que tras toda una vida, realizaron estos niños y niñas o sus familiares. Unas consideraciones marcadas, en ocasiones, por el brusco cambio o trauma que supuso este exilio, como nos explica el hijo de Ángel Múgica "el trauma nunca lo abandonó... era constante. Y cuando vio la oportunidad, habló de ello a todos los que querían escucharle. Él estaba constantemente haciéndolo" (MÚGICA, 2012), testimonio que coincide con el de su esposa: "un drama que nunca podía salir de su mente, jamás. Nunca. Y cuando al final él estaba senil le oía a veces en la noche que estaba llorando. Y luego decía "mi padre, mi padre", diciendo las cosas que él pensaba". (VAN OVERBEKE, 2012). Pero aunque la memoria les hiciese difícil recordar estos momentos, "no sé, eso fue hace mucho tiempo. Es decir, ¿qué voy a decir, de hace 75 años?" (ROLDÁN, 2012), algunos recuerdan esta experiencia como positiva dentro de las circunstancias excepcionales, al haber podido encontrar en Bélgica un hogar, "un nido seguro, y así de esa manera en realidad una infancia despreocupada". (FAKKEL, 2012).

Varios testimonios coinciden en dudar de si el exilio fue la mejor solución, por lo dramática y traumática que resultó. Si hubiesen podido elegir, hubieran preferido cualquier otra alternativa diferente a la de tener que separarse de sus padres, hermanos y familiares. Cualquier solución la habrían considerado mejor a la del exilio con tal de evitar esta negativa experiencia, "cuanto más viejo se convirtió, más decía a menudo, 'debería haber hecho algo distinto, nunca enviar a su hijo lejos'. Morimos juntos si es necesario o vivimos" (VAN OVERBEKE, 2012), una opinión muy dura y aterradora compartida por Santiago Roldán, que hubiese preferido también una alternativa al exilio: "hay quienes dicen que a veces hubiera sido mejor que los padres a sus hijos les hubiesen perdido en vez de simplemente 
darlos"2. (ROLDÁN, 2012).

Desafortunadamente, parece ser que la historia se repite una y otra vez y no aprendemos estas lecciones. Los constantes dramas bélicos que azotan nuestra sociedad en la actualidad (no hay más que fijar nuestra mirada en lo que está sucediendo en Siria, entre muchos otros ejemplos, desde hace unos años), si bien movilizan a parte de la sociedad civil y a organismos internacionales, ponen en evidencia la ceguera e inacción de los gobiernos ante el gran número de exiliados y refugiados, de entre los cuales, la peor parte la sufren los más pequeños. Como manifestaba Néstor Folla:

\begin{abstract}
Es estúpido a todo esto, es que el mundo no aprende, oye. La Guerra Civil española fue una guerra muy sucia, y cuando ves lo que pasó después, incluso aquí en Europa... Cuando ves lo que sucedió en Yugoslavia, muchos años más tarde. La gente no aprende del sufrimiento y del dolor de los demás. Sólo cuando experimentan ellos mismos empiezan a pensar. (FOLLA, 2012).
\end{abstract}

Esperemos que, al menos este tipo de estudios académicos, pero sobretodo de memoria histórica y recuerdo a la infancia exiliada, nos sirvan para reflexionar un poco más sobre parte de nuestro pasado educativo, bélico y social, para ayudar a construir una conciencia colectiva más crítica, conocedora de sus antecedentes y consciente de la necesidad e importancia de la educación, la atención y el cuidado a la infancia en circunstancias tan especiales como las guerras. Asimismo, también consideramos oportuno para finalizar, valorar y destacar la labor de todas aquellas personas e iniciativas que en el pasado movilizaron a familias, sindicatos y organizaciones civiles, para atender a estos niños y niñas que, a pesar de todo, pudieron encontrar un nuevo hogar en otro país y que, gracias a las oportunidades educativas y culturales, disfrutaron una vida plena con sus familias de acogida.

\title{
Referencias
}

ALONSO CARBALLÉS, Jesús J. 1937. Los niños vascos evacuados a Francia y

Bélgica. Historia y memoria de un éxodo infantil, 1936-1940. Bilbao: Asociación de niños evacuados el 37, 1998.

ALTED VICIL, Alicia; GONZÁLEZ, Roger; MILLÁN, María José. El exilio de los niños. Madrid: Fundación Francisco Largo Caballero y Fundación Pablo Iglesias, 2003.

ALTED VIGIL, Alicia. El 'instante congelado' del exilio de los niños de la guerra civil española. DEP. Deportate, esuli, profughe, 3, 2005, p. 263-281.

ARAGÜES ESTRAGUÉS, Rosa María. El éxodo de los niños republicanos en la guerra civil: Primitiva Francés Casanova, 1936-1939. Hispania Nova: Revista de historia contemporánea, 13, p. 78-98, 2015.

BARRENETXEA MARAÑÓN, Igor. Los niños de la guerra: entre la historia oral, el cine y la memoria. Historia contemporánea, 45, p. 741-768, 2012.

BELL, Adrián. Sólo serán tres meses: los niños vascos refugiados en el exilio.

\footnotetext{
${ }^{2}$ En la exposición "Entre España y Rusia. Recuperando la historia de los niños de la guerra" se podían encontrar declaraciones similares: "Mi madre había llegado demasiado tarde y ya no la necesitaba". "No elegimos el exilio, nos encontramos con que nos habían exiliado". "Nos salvaron de la guerra pero nos perdieron para siempre". El Diario.es, 20 de abril de 2014. Disponible en: <http://www.eldiario.es/andalucia/ salvaron-guerra-perdieron-siempre_0_313219313.html>. Consultado el: 2 abril 2017.
} 
Barcelona: Plataforma, 2011.

BERGUER, Geraldine. Les enfants de la Guerre Civile espagnole. Chronique du périple des enfants espagnols réfugiés en Bélgique. Mons: École d'Interprètes Internationaux, Université de Mons, 1991.

DE DIOS FERNÁNDEZ, Eider. Los hilos de la memoria: investigación y método a través de la historia oral. In: COLOMER, Juan Carlos; ESTEVE, Javier; IBÁÑEZ, Mélanie (Coord.). Ayer y hoy: Debates, historiografía y didáctica de la Historia. València: Universitat de València, Asociación de Historia Contemporánea, 2015. p. 57-62.

EECKHOUT, Tania. De hulp aan republikeins Spanje uitgaande van de BWP, afdeling Gent-Eeklo, meer specifiek de opvang der Spaanse kinderen. Revue Belge d'Histoire Contemporaine-Belgisch Tijdshrift voor Nieuwste Geschiedenis, Bruxelles, v. XVIII, 1-2, p. 240-246, 1987.

EGIDO LEÓN, Ángeles. El testimonio oral y las historias de la vida: el exilio español de 1939. Migraciones \& Exilios: Cuadernos de la Asociación para el estudio de los exilios y migraciones ibéricos contemporáneos, 10, p. 83-99, 2009.

. Trabajando con la memoria: exilio y fuente oral. Historia y comunicación social, 6, p. 267-279, 2001.

ELOY, Sarah. De Spaanse migratie naar België gedurende de 19de en 20ste eeuw. "Los Niños de la Guerra": Een casus. Gent: Universiteit Gent, 2005.

ESCRIVÁ MOSCARDÓ, Cristina. La Colonia infantil de Bellús. 512 escolares salvados de la guerra: la infancia, el tesoro de la Segunda República. Xàtiva: Ulleye, 2014.

ESCRIVÀ MOSCARDÓ, Cristina; MAESTRE MARIN, Rafael. De las negras bombas a las doradas naranjas. Colonias escolares 1936-1939. Valencia: L'Eixam Edicions, 2011.

GAGO GONZÁLEZ, José María. Las fuentes orales y el exilio. Migraciones \& Exilios: Cuadernos de la Asociación para el estudio de los exilios y migraciones ibéricos contemporáneos, 8, p. 121-135, 2007.

LABAJOS PÉREZ, Emilia; VITORIA GARCÍA, Fernando. Los niños españoles refugiados en Bélgica (1936-1939). Namur: Asociación de los niños de la guerra, 1997.

LEGARETTA, Dorothy. Hospitality to the Basque refugee children in Belgium. Belgisch tijdschrift voor Nieuwste Geschiedenis, XVIII, p. 275-288, 1987.

LEGARETTA, Dorothy. The Gernica Generation. Basque refugee children of the Spanish Civil War. Reno: University of Nevada, 1987.

PAYÀ RICO, Andrés. Reconstruyendo historias del exilio infantil en Bélgica. Iber: Didáctica de las ciencias sociales, geografía e historia, 81, p. 51-56, 2015.

Spaanse Kinderen. Los niños españoles exiliados en Bélgica durante la Guerra Civil. Experiencia pedagógica e historias de vida. El futuro del pasado, 4, p. 191-205, 2013.

SALINAS, Carlos. Lugares de memoria de la guerra civil. Las colonias infantiles en la provincia de Alicante. Clío: History and History Teaching, 40, 2014. Disponible en: <http://clio.rediris.es/n40/articulos/salinas2014.pdf>. Acceso em: 5 mar. 2017. 
la Universitat Oberta de Catalunya (UOC). Director del Departamento de Educación Comparada e Historia de la Educación de la UV. Coeditor de la revista Espacio, Tiempo y Educación, y del Consejo de redacción de la revista Educació i Història. Revista d'Història de I'Educació. Actualmente es miembro de la Junta Directiva de la Sociedad Española de Historia de la Educación (SEDHE).

Dirección postal: Facultad de Filosofía y Ciencias de la Educación, Avenida Blasco Ibáñez, 30, 46010, Valencia, España.

E-mail: andres.paya@uv.es

Recebido em 25 de abril de 2017.

Aceito em 21 de fevereiro de 2018. 